\title{
Peningkatan Keselamatan Lalu Lintas Pada Ruas Jalan Hayam Wuruk Di Kabupaten Jember
}

\author{
Elvira Azizah*1, Wijianto², Alfath S.N. Syaban ${ }^{3}$ \\ Politeknik Transportasi Darat Indonesia \\ Jl. Raya Setu No.89, Cibuntu, Kec. Cibitung, Bekasi, Jawa Barat \\ e-mail: *elvira@gmail.com \\ Received 11-10-2021; Reviewed 01-11-2021; Accepted 22-11-2021 \\ Journal Homepage: http://ktj.pktj.ac.id/index.php/ktj \\ DOI: $10.46447 / \mathrm{ktj} . \mathrm{v} 8 \mathrm{i} 2.404$
}

\begin{abstract}
The number of accidents that occurred in Jember Regency during the last 5 (five) years has decreased, although in some years there has been an increase and caused the number of fatalities (death, serious injuries, minor injuries) to increase every year. From the data obtained, it can be seen that one of the roads that often has accidents is the Hayam Wuruk road. Traffic flow and speed conditions on the Hayam Wuruk road are quite high due to its function as arterial roads and national roads, but the land use around these roads which includes shops, shopping centers, offices, and schools causes frequent conflicts and traffic problems. especially in the field of road safety, both driver safety and pedestrian safety. This study aims to increase the level of safety in traffic for both drivers and pedestrians on the Hayam Wuruk road, Jember Regency. The research was carried out by observing and identifying the existing conditions along the Hayam Wuruk road including road performance conditions, traffic safety conditions and behavioral conditions of road users on these roads, in order to obtain handling proposals based on the results of the analysis. The results showed that the high number of accidents on the Hayam Wuruk road in Jember district was mostly caused by errors from human factors. In addition to the causes of accidents based on speed, there were also accidents based on perspective, which was influenced by visibility to stop when seeing the vehicle in front. The Zebra Cross facility which is intended for the community has not yet been fulfilled. A social approach is needed in the form of increasing awareness and safety for drivers.
\end{abstract}

Keywords: Traffic safety, Road user behavior, Traffic accidents

\begin{abstract}
Abstrak
Jumlah kecelakaan yang terjadi di kabupaten Jember selama 5 (lima) tahun terakhir mengalami penurunan, walaupun pada beberapa tahun terjadi kenaikan dan menyebabkan jumlah korban jiwa (meninggal, luka berat, luka ringan) semakin bertambah setiap tahunnya. Dari data yang diperoleh, dapat diketahui bahwa salah satu ruas jalan sering terdapat kejadian kecelakaan adalah jalan Hayam Wuruk. Kondisi arus lalu lintas dan kecepatan pada ruas jalan Hayam Wuruk cukup tinggi dikarenakan fungsinya sebagai jalan arteri dan jalan nasional, namun tata guna lahan di sekitar ruas jalan tersebut yang meliputi pertokoan, pusat perbelanjaan, perkantoran, dan sekolah menyebabkan sering terjadinya konflik dan permasalahan lalu lintas terutama di bidang keselamatan jalan, baik keselamatan pengemudi maupun keselamatan pejalan kaki. Penelitian ini bertujuan untuk meningkatkan tingkat keselamatan dalam berlalu lintas baik bagi pengemudi maupun bagi pejalan kaki
\end{abstract}


pada ruas jalan Hayam Wuruk Kabupaten Jember. Penelitian dilaksanakan dengan melakukan observasi dan identifikasi kondisi eksisting di sepanjang ruas jalan Hayam Wuruk meliputi kondisi kinerja jalan, kondisi keselamatan lalu lintas dan kondisi perilaku pengguna jalan pada ruas jalan tersebut, sehingga didapat usulan penangan berdasarkan hasil analisis. Hasil penelitian menunjukkan bahwa tingginya jumlah kejadian kecelakaan pada ruas jalan Hayam Wuruk di kabupaten Jember sebagian besar disebabkan oleh kesalahan dari faktor manusia.Selain penyebab kecelakaan berdasarkan kecepatan ada juga kecelakaan berdasarkan pandangan yaitu dipengaruhi jarak pandang untuk berhenti pada saat melihat kendaraan yang berada didepan. Fasilitas Zebra Cross yang diperuntukan bagi masyarakat masih belum memenuhi. Diperlukan pendekatan sosial berupa peningkatan kewaspadaan dan keselamatan bagi pengemudi.

Kata kunci: Keselamatan lalu lintas, Perilaku pengguna jalan, Kecelakaan lalu lintas

\section{PENDAHULUAN}

Keselamatan lalulintas merupakan salah satu bagian yang penting dalam rekayasa lalulintas untuk mencapai tujuan teknik lalulintas yang aman, nyaman, dan ekonomis (Mahardianto, 2015). Selanjutnya Keselamatan transportasi juga merupakan masalah global (Oktopianto, Nabil, et al., 2021). Analisis keselamatan jalan dapat dilakukan sebagai upaya untuk mengetahui penanganan yang tepat terhadap daerah rawan kecelakaan lalu lintas (Oktopianto, Shofiah, et al., 2021). Masalah kecelakaan lalu lintas menjadi suatu hal yang vital yang perlu dilakukan kajian terhadapnya, baik mengenai penyebab, akibat, dan penanganannya (Oktopianto \& Pangesty, 2021).

Penelitian terdahulu mengungkapkan tingkat keselamatan lalu lintas di Kota Semarang terjadi penurunan, dengan upaya penanganan serius oleh Pemerintah Kota Semarang dengan melibatkan seluruh stakeholder (Ruktiningsih, 2017). Langkah-langkah kebijakan yang tepat sasaran dan tepat guna untuk meningkatkan kepatuhan terhadap peraturan lalu lintas penting di tegaskan. Secara keseluruhan, penegakan hukum tunggal terbukti tidak mengurangi risiko kecelakaan dalam jangka panjang. Strategi penegakan hukum yang menggabungkan beberapa kebijakan untuk meningkatkan kepatuhan pengguna jalan pada umumnya lebih efisien (Darmansyah \& Prasetyanto, 2019). Menteri Perhubungan RI telah mengeluarkan Praturan Nomor 26 tahun 2015 tentang Standar Keselamatan Lalu Lintas dan Angkutan Jalan yang bertujuan meminimalisir terjadinya kecelakaan di jalan raya. Adanya peraturan tersebut tentu dapat meminimalisir terjadinya kecelakaan apabila implementasinya diterapkan dengan baik oleh para pengguna kendaraan (Pinayungan et al., 2018). Untuk dapat memberikan efek jera kepada pengendara yang melanggar undang-undang lalu lintas, harus ada upaya penindakan dari aparat penegak hukum baik di proses secara administrasi maupun secara pidana (Fahria \& Faisal, 2019). Dengan adanya peningkatan jumlah kecelakaan sedangkan indeks fatalitas mengalami penurunan maka tingkat keselamatan lalu lintas jalan mengalami peningkatan hal ini tidak lepas dari dukungan semua pihak bila perlu terus ditekan dengan meningkatkan kesadaran masyarakat dalam membangun budaya tertib berlalu lintas (Novita Sari \& Afriandini, 2021).

Upaya optimalisasi dalam menanggulangi kecelakaan lalu lintas adalah memaksimalkan sosialisasi tata cara pengangkutan yang benar kepada para pengusaha pemilik barang, transporter dan pengemudi yang bekerja sama dengan dinas perhubungan Kabupaten Gresik, melakukan sosialisasi pentingnya melakukan 
pengujian kendaraan bermotor, bekerja sama dengan pihak asuransi kendaraan untuk menghilangkan asuransi kecelakaan akibat pelanggaran muatan, dan memaksimalkan rekayasa lalu lintas untuk melakukan penataan moda share material (Parwita, 2020). Strategi dalam meningkatkan kesadaran hukum masyarakat antara lain: Pertama, sosialisasi atau kampanye untuk mematuhi peraturan lalu lintas melalui pemasangan spanduk dan sosialisasi. Kedua, Membangun karakter disiplin (Desril et al., 2018). Selanjutnya, pendekatan represif adalah untuk melakukan operasi rutin dan operasi bersama dalam rangka meminimalkan jumlah kematian korban kecelakaan lalu lintas (Setiawan, 2020). Didalam memecahkan masalah keselamatan dan kecelakaan jalan, manajemen lalu lintas menjadi faktor penting. Untuk itu sangatlah penting untuk mengembangkan sistem informasi keselamatan dan kecelakaan jalan sebagai implementasi dari manajemen lalu lintas itu sendiri (Sriastuti \& Asmani, 2019).

Jika ditinjau dari segi teknis kecelakaan lalu lintas adalah aspek negatif dari peningkatan arus transportasi mobilitas tanpa peningkatan infrastruktur yang menempatkan fungsi keselamatan. Infrastruktur jalan dan fasilitas peralatan, jarak pandang, radius putar, dan juga kondisi putar balik serta tata letak fasilitas (Samsudin, 2020). Oleh karenanya, audit keselamatan jalan dan tindakan pencegahan secara komprehensif (aspek teknis dan non teknis) perlu segera dilakukan (Zanuardi \& Suprayitno, 2018). Berdasarkan data dari Polres Kabupaten Jember dari total kejadian kecelakaan, Jalan Hayam Wuruk merupakan peringkat kedua tahun 2016-2020. Oleh karena itu dibutuhkan Penelitian untuk memecahkan masalah yang terjadi di ruas jalan tersebut. Serta, memberikan alternatif solusi yang tepat bagi masyarakat untuk mengurangi kecelakaan dan melakukan upaya peningkatan keselamatan bagi pengguna jalan di ruas jalan Hayam Wuruk.

\section{METODE PENELITIAN}

Penelitian ini dilakukan dengan menggunakan metode penelitian survey. Penelitian survey pada umumnya dilakukan untuk mengambil suatu generasi dari pengamatan yang tidak mendalam. Walaupun metode survey ini tidak memerlukan kelompok kontrol seperti halnya pada metode eksperimen, namun generasi yang dilakukan bisa lebih akurat bila digunakan sampel yang representative (Sugiyono, 2005).

Metode Pengumpulan Data :

Pegumpulan Data Sekunder Data ini diperoleh melalui instnasi terkait yaitu Kepolisian Kabupaten Jember selama 5 (lima) tahun terakhir yaitu tahun 2016 - 2020. Pengumpulan Data Primer Data yang diperoleh secara langsung, dalam bentuk survei lapangan, dengan tujuan untuk mengetahui kondisi eksisting guna merumuskan permasalahan yang harus ditangani. Data primer yang dibutuhkan antara lain :

1. Survei Inventarisasi Prasarana Jalan

Survei ini bertujuan untuk mengetahui rambu, marka, fasilitas pejalan kaki dan perilaku pejalan kaki di jalan Hayam Wuruk secara eksisting untuk membandingkan dengan standar jalan perkotaan.

2. Survei Kecepatan

Survei kecepatan didapatkan dari pengamatan di lapangan dan penembakan kendaraan menggunakan Speed Gun agar mengetahui kecepatan masing-masing kecepatan kendaraan. 
3. Survei Perilaku Pengguna Jalan

4. Survei ini bertujuan untuk mengetahui perilaku pengemudi dalam penggunaan helm, penyalaan lampu kendaraan pada siang hari dan menggunakan hp saat berkendara.

\section{HASIL DAN PEMBAHASAN}

\section{a. Inventarisasi Kondisi Ruas Jalan Hayam Wuruk}

Kondisi di ruas jalan Hayam Wuruk yang di survei, ditemukan dengan kondisi infrakstruktur cukup baik namun terdapat marka penyeberangan pejalan kaki yang sudah pudar dan rambu ada yang terhalang tiang listrik.

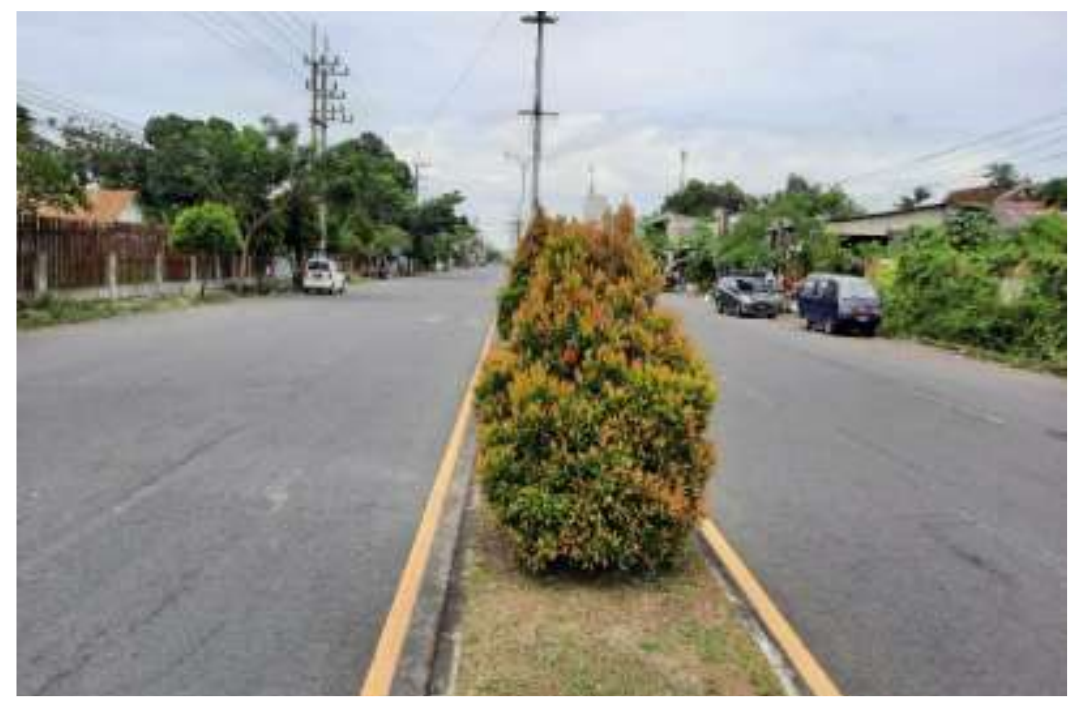

Gambar 1. Kondisi Eksisting Jalan Hayam Wuruk

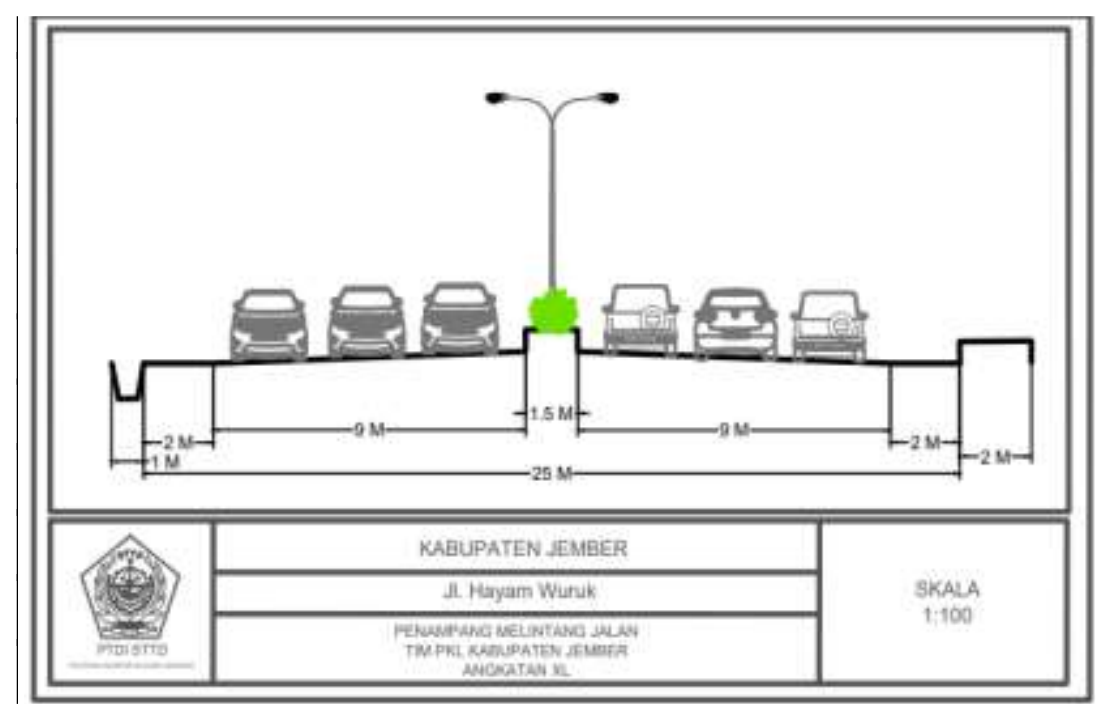

Gambar 2. Penampang Melintang Jalan 
Tabel 1. Inventarisasi Kondisi Ruas Jalan Hayam Wuruk

\begin{tabular}{|c|c|c|c|}
\hline \multirow[t]{3}{*}{ Nama Jalan } & \multicolumn{3}{|c|}{ Geometrik Jalan } \\
\hline & Nadi & Awal & 208 \\
\hline & Touc & Akhir & 701 \\
\hline & 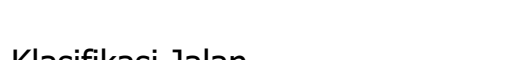 & Status & Nasional \\
\hline & 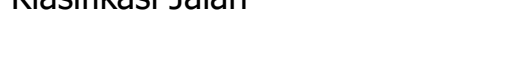 & Fungsi & Arteri \\
\hline & Tipe Jalan & & $6 / 2 D$ \\
\hline & Model Arus & & 2 Arah \\
\hline & Panjang Jalan & $\mathrm{m}$ & 2600 \\
\hline & Lebar Jalan Total & $\mathrm{m}$ & 22 \\
\hline & Tumbar & Lajur & 6 \\
\hline & (Munian & Jalur & 2 \\
\hline & Lebar Jalur Efektif (Dua Arah) & $\mathrm{m}$ & 9 \\
\hline & Lebar Perlajuan & $\mathrm{m}$ & 3 \\
\hline & Median & $\mathrm{m}$ & 1,5 \\
\hline \multirow{15}{*}{ Jalan Hayam Wuruk } & Trutoar & Kiri & - \\
\hline & Hotual & Kanan & 2 \\
\hline & Bahu Talan & Kiri & 2 \\
\hline & & Kanan & 2 \\
\hline & Drainace & Kiri & 1 \\
\hline & Diantase & Kanan & - \\
\hline & Kondisi Jalan & & Baik \\
\hline & Jenis Perkerasan & & Aspal \\
\hline & Hambatan Samping & & Sedang \\
\hline & Jumlah Lampu Penerangan Jalan & & 65 \\
\hline & & Jumlah & 20 \\
\hline & Rabu & Kesesuaian & Sesuai \\
\hline & & Kondisi & Baik \\
\hline & Parkir Street & & - \\
\hline & Marka & & Pudar \\
\hline
\end{tabular}

\section{b. Perilaku Pengguna Jalan}

Tingkat kedisplinan atau perilaku pengemudi dapat dilihat dari tinggi rendahnya penyalaan lampu, penggunaan helm dan sabuk keselamatan di ruas-ruas jalan khususnya di jalan-jalan dengan tingkat kecelakaan yang tinggi. 
Tabel 2. Perilaku Pengguna Jalan

\begin{tabular}{|c|c|c|c|c|c|c|c|c|c|c|c|c|c|c|c|c|}
\hline \multirow{4}{*}{ No } & \multirow{4}{*}{ Peak } & \multirow{4}{*}{$\begin{array}{l}\text { Nama } \\
\text { Ruas }\end{array}$} & \multicolumn{2}{|c|}{$\begin{array}{l}\text { Sampel (30 } \\
\text { Kendaraan) }\end{array}$} & \multicolumn{12}{|c|}{ Sepeda Motor } \\
\hline & & & \multirow{3}{*}{ Masuk } & \multirow{3}{*}{ Keluar } & \multirow{2}{*}{\multicolumn{2}{|c|}{$\begin{array}{c}\text { Tidak } \\
\text { Menggunkan } \\
\text { Helm }\end{array}$}} & \multirow{2}{*}{\multicolumn{2}{|c|}{$\begin{array}{c}\text { Menggunakan } \\
\text { Helm }\end{array}$}} & \multirow{2}{*}{\multicolumn{2}{|c|}{$\begin{array}{c}\text { Tidak } \\
\text { Menyalakan } \\
\text { Lampu }\end{array}$}} & \multirow{2}{*}{\multicolumn{2}{|c|}{$\begin{array}{l}\text { Menyalakan } \\
\text { Lampu }\end{array}$}} & \multicolumn{4}{|c|}{ Aktifitas Lain } \\
\hline & & & & & & & & & & & & & Mens & brol & Ber & $\begin{array}{l}\text { nain } \\
\text { P }\end{array}$ \\
\hline & & & & & $\mathbf{M}$ & $\mathbf{K}$ & $\mathbf{M}$ & $\mathbf{K}$ & $\mathbf{M}$ & $\mathbf{K}$ & $\mathbf{M}$ & $\mathbf{K}$ & $\mathbf{M}$ & $\mathbf{K}$ & $\mathbf{M}$ & $\mathbf{K}$ \\
\hline \multirow[t]{3}{*}{1} & Pagi & $\begin{array}{c}\text { Jl Hayam } \\
\text { Wuruk } \\
\text { Kaliwates }\end{array}$ & 30 & 30 & 9 & 8 & 21 & 22 & 28 & 27 & 2 & 3 & 1 & 0 & 1 & 1 \\
\hline & \multicolumn{2}{|c|}{ Jumlah } & 30 & 30 & 9 & 8 & 21 & 22 & 28 & 27 & 2 & 3 & 1 & 0 & 1 & 1 \\
\hline & & & & & $30 \%$ & $27 \%$ & $70 \%$ & $73 \%$ & $93 \%$ & $90 \%$ & $7 \%$ & $10 \%$ & $3 \%$ & $0 \%$ & $3 \%$ & $3 \%$ \\
\hline
\end{tabular}

\section{c. Desain Jalan Berkeselamatan}

Ada beberapa hal yang wajib dilakukan untuk memperbaiki dalam jangka pendek di ruas jalan Hayam Wuruk yaitu pihak Dinas Perhubungan berkoordinasi dengan Kepolisian melakukan sosialisasi kepada masyarakat tentang tata cara berkendara yang baik misalnya menggunakan helm saat berkendara, menyalakan lampu pada siang hari, tidak menggunakan handphone saat sedang berkendara untuk menurunkan angka kecelakaan di Kabupaten Jember. Hal lainnya yang perlu dilakukan yaitu Usia rawan kecelakaan kisaran usia 17-25 tahun maka perlu diadakan di sekolah-sekolah yang berada di Kabupaten Jember tentang tata cara berkendara yang berkeselamatan. Melakukan perbaikan atau pengadaan baru untuk marka dan rambu yang telah rusak agar pengendara dapat melihat jelas saat sedang berkendara. Penanganan lain seperti pada penelitian sebelumnya pada titik rawan kecelakaan bisa berupa pengadaan rambu batas kecepatan, rambu peringatan persimpangan, rambu petunjuk putar balik, rambu peringatan DRK, rambu hati-hati, pengadaan APILL dengan satu warna (kuning), perbaikan marka dan sosialisasi terhadap masyarakat (Oktopianto, Prasetyo, et al., 2021).

\section{SIMPULAN}

Berdasarkan hasil analisis data serta pemecahan masalah maka dapat di ambil kejadian kecelakaan yang terjadi di ruas Jalan Hayam Wuruk dikarenakan pada jalan tersebut belum terdapat rambu batas kecepatan, dari data kronologi kecelakaan yang diperoleh dari kepolisian, penyebab utama kecelakaan adalah batas kecepatan kendaraan melebihi standar yang seharusnya yaitu 60KM/JAM berdasarkan kelas jalan Nasional dengan fungsi jalan Arteri. Selain penyebab kecelakaan berdasarkan kecepatan ada juga kecelakaan berdasarkan pandangan, dari kronologi kecelakaan pada tanggal 13 dan 19 Pada Bulan Juli 2020, dipengaruhi jarak pandang untuk berhenti pada saat melihat kendaraan yang berada didepan. Fasilitas Zebra Cross yang diperuntukan bagi masyarakat masih belum memenuhi syarat. Dimana, Zebra Cross tersebut sudah mulai Pudar. Sama halnya dengan marka yang ada pada Ruas Jalan Hayam Wuruk juga sudah mulai pudar. Pada titik kecelakaan yang terjadi pada 
simpang-simpang jalan Hayam Wuruk yang belum terdapat rambu hati-hati daerah rawan kecelakaan, sehingga kecelakaan terjadi karena kendaraan yang masuk pada Jalan Hayam Wuruk tidak melihat kendaraan yang datang dari arah sisi kanan maupun kiri Jalan Hayam Wuruk.

\section{DAFTAR PUSTAKA}

Darmansyah, F., \& Prasetyanto, D. (2019). STRATEGI PENEGAKAN HUKUM DALAM MENINGKATKAN KESELAMATAN LALU LINTAS DI KOTA BANDUNG. Jurnal Transportasi, 19(1). https://doi.org/10.26593/jt.v19i1.3258.11-20

Desril, R., Elviandri, E., Aksar, A., Raihana, R., Sommaliagustina, D., \& Lestari, T. W. (2018). PENYULUHAN HUKUM KESELAMATAN LALU LINTAS: Strategi Mewujudkan Budaya Patuh Hukum Lalu Lintas. Jurnal Pengabdian UntukMu NegeRI, 2(2). https://doi.org/10.37859/jpumri.v2i2.764

Fahria, F., \& Faisal, F. (2019). PENEGAKAN HUKUM TERHADAP PELANGGARAN ANGKUTAN JALAN DALAM BERLALU LINTAS DI KOTA TERNATE. De Jure Jurnal IImiah IImu Hukum, 1(1). https://doi.org/10.33387/dejure.v1i1.1415

Mahardianto. (2015). Audit Keselamatan Jalan Di Ruas Bts. Banyumas Tengah Kebumen Km 171 - 172 Semarang.

Novita Sari, C. A., \& Afriandini, B. (2021). ANALISA TINGKAT KECELAKAAN LALU LINTAS GUNA MENINGKATKAN KESELAMATAN JALAN DI KOTA YOGYAKARTA. CIVeng: Jurnal Teknik Sipil Dan Lingkungan, 2(1). https://doi.org/10.30595/civeng.v2i1.9883

Oktopianto, Y., Nabil, M. J., \& Arief, Y. M. (2021). SOSIALISASI KESELAMATAN TRANSPORTASI JALAN PENGEMUDI GOJEK DI KOTA TEGAL. Kumawula: Jurnal Pengabdian Kepada Masyarakat, 4(2), $242 \quad$ - 248. https://doi.org/10.24198/kumawula.v4i2.33321

Oktopianto, Y., \& Pangesty, S. (2021). Analisis Daerah Lokasi Rawan Kecelakaan Jalan Tol Tangerang-Merak. Jurnal Keselamatan Transportasi Jalan (Indonesian Journal of Road Safety), 8(1), 26-37. https://doi.org/10.46447/ktj.v8i1.301

Oktopianto, Y., Prasetyo, T., \& Maulana Arief, Y. (2021). Analisis Penanganan Daerah Rawan Kecelakaan Kabupaten Karanganyar. Borneo Engineering: Jurnal Teknik Sipil, 5(2), 201-214. https://doi.org/10.35334/be.v5i2.2018

Oktopianto, Y., Shofiah, S., Rokhman, F. A., Wijayanthi, K. P., \& Krisdayanti, E. (2021). Analisis Daerah Rawan Kecelakaan (Black Site) Dan Titik Rawan Kecelakaan (Black Spot) Provinsi Lampung. Borneo Engineering: Jurnal Teknik Sipil, 5(1), 40-51. https://doi.org/10.35334/be.v5i1.1777

Parwita, I. M. (2020). Optimalisasi satuan lalu lintas Polres Gresik dalam menanggulangi kecelakaan lalu lintas akibat pelanggaran muatan. Jurnal Sosiologi Dialektika, 14(1). https://doi.org/10.20473/jsd.v14i1.2019.44-51

Pinayungan, J., Kusmanto, H., \& Isnaini, I. (2018). Implementasi Peraturan Menteri Perhubungan Republik Indonesia Tentang Standar Keselamatan Lalu Lintas Dan Angkutan Jalan. Jurnal Administrasi Publik: Public Administration Journal, 8(1). https://doi.org/10.31289/jap.v8i1.1581

Ruktiningsih, R. (2017). ANALISIS TINGKAT KESELAMATAN LALU LINTAS KOTA SEMARANG. G - SMART, 1(1). https://doi.org/10.24167/gs.v1i1.919

Samsudin, I. (2020). ANALISA FAKTOR PENYEBAB KECELAKAAN PADA RUAS JALAN Ir. H. ALALA KOTA KENDARI DITINJAU DARI PRASARANA DAN GEOMETRIK 
JALAN. Jurnal Penelitian Transportasi Darat, 21(1). https://doi.org/10.25104/jptd.v21i1.1166

Setiawan, F. D. (2020). Penanggulangan fatalitas korban kecelakaan lalu lintas di kawasan Tugurejo Ngasem Kediri, Jawa Timur. Jurnal Sosiologi Dialektika, 15(2). https://doi.org/10.20473/jsd.v15i2.2020.128-134

Sriastuti, D. A. N., \& Asmani, A. A. R. (2019). Pengembangan Sistem Informasi Kecelakaan Melalui Upaya Keselamatan Jalan Sebagai Implementasi Efisiensi Manajemen Lalu Lintas. Paduraksa, 8(1).

Zanuardi, A., \& Suprayitno, H. (2018). Analisa Karakteristik Kecelakaan Lalu Lintas di Jalan Ahmad Yani Surabaya melalui Pendekatan Knowledge Discovery in Database. Jurnal Manejemen Aset Infrastruktur \& Fasilitas, 2(1). https://doi.org/10.12962/j26151847.v2i1.3767 